\title{
BDA Indemnity
}

Peter Ward

Managing Director BDA

The BDJ Upfront section includes editorials, letters, news, book reviews and interviews. Please direct your correspondence to the News Editor,

Adrian O'Dowd at BDJNews@nature.com. Press releases or articles may be edited, and should include a colour photograph if possible.

$\mathrm{T}$ he British Dental Association is on the cusp of a major innovation. This summer, we will launch a wholly new service for members - BDA Indemnity. Integrated within our suite of well-established member offerings, Indemnity will provide further support to that which the BDA is proud to offer UK dentists. As a member-owned, not-for-profit organisation with a long heritage, the BDA has a clear and undiluted purpose the support of UK dentists in their professional careers and care of patients.

After many years of regarding the provision of professional indemnity as the work of others, the BDA has concluded that there are systemic challenges within current provision. Our members have told us they are dissatisfied with the service they are currently receiving. The General Dental Practice Committee (GDPC) has questioned the modus operandi of a number of the extant players. For two years running, the national conference of Local Dental Committees has debated motions on perceived shortcomings of indemnity arrangements. The debates have centred upon price, transparency and perceived arbitrariness of approach. The government has also raised its own concerns about the adequacy and fitness of current indemnity arrangements for a number of other reasons, not least financial security. Whether we like it or not, the rubric of the recent public consultation on indemnity declares an undisguised policy position that considers the historic 'mutual' 'discretionary' arrangements to be unacceptable. The proposition tested by the consultation is that in the future, indemnity should be made more certain for patients and underwritten by contract. It suggests that providers of indemnity should be subject to the same financial and prudential (solvency) regulations that oversee the delivery of formal insurance. The GDC also shares this view. ${ }^{2}$

Our conclusion, having studied a range of options, held discussions with stakeholders and considered the government consultation is that change is inevitable and that the only way to address these matters is by creating a solution of our own.

BDA Indemnity will offer dentist-to-dentist support. It is backed by a legally enforceable insurance contract with Royal and Sun Alliance Insurance Limited - one of the top five insurance companies in the UK (Standard \& Poor's credit rating 20 June 2018). The cover will include true indemnity cover as statutorily required by the GDC ( $£ 10$ million limit for claims in any one year) and legal expenses insurance to ensure that dentists can obtain legal assistance at the systems, processes and compliance documents in place to help us in this highly regulated environment. Our unique role as the representative of dentists means that we have finessed the contract terms and argued the details in a way that individual dentists could never do.

$\boldsymbol{B D A}$ Indemnity is designed to represent 'best-of-breed' in today's market. Vitally, being an insurance backed product, it will be future-proofed against any fall-out from the consultation. We will be telling you more over coming weeks and will be very visible at the British Dental Conference and Dentistry Show in May. The service will go

\section{'This summer, we will launch a wholly new service for members - BDA Indemnity'}

GDC, tribunals and other legal hearings. Both these aspects will be offered as occurrence-based cover which means that it continues in perpetuity as opposed to the less satisfactory 'claims made' alternative favoured by most insurers. By limiting the availability of this indemnity to UK dentists only (and excluding maxillo-facial surgery) we can ensure that there are no cross-subsidies to other professions or other countries - it is UK dentists sharing the risks with other UK dentists. The cover will be easily accessible via an online click, quote and apply service and will be flexed in a way that fairly reflects individual practising circumstances.

This has taken a lot of work and a lot of thought. We have taken advice from recognised industry experts and are supported by our insurance broker colleagues at Lloyd \& Whyte Ltd, who are authorised and regulated by the Financial Conduct Authority (FCA). We have been approved as an appointed representative of Lloyd \& Whyte Ltd which means, they ensure we have the necessary live on Monday 3 June. As well as being fully protected from any 'legacy' claims arising from treatment in past years. We genuinely believe it delivers the best of both worlds.

Together, we are stronger!

\section{Acknowledgments}

The policy is arranged by the British Dental Association and underwritten by Royal \& Sun Alliance. The British Dental Association is an appointed representative of Lloyd \& Whyte Ltd. Lloyd \& Whyte Ltd is authorised and regulated by the Financial Conduct Authority (FCA). The FCA does not regulate the advice you receive with regards to Advisory, Case Management and Indemnity Support provided by the BDA. Information about the policy can be found at bda.org/ indemnity. A paper copy can be made available upon request.Email indemnity@bda.org.

\section{References}

1. Department of Health and Social Care. Appropriate clinical negligence cover: A consultation on appropriate clinical negligence cover for regulated healthcare professionals and strengthening patient recourse. Updated 2019.

2. Drummond R. Letter to Acute Care and Quality Directorate, Department of Health and Social Care. General Dental Council. 2019.

DOI: $10.1038 / 541415-019-0163-4$ 